\title{
Das parteiras à medicina obstétrica: uma breve reflexão sobre o processo de cientificização do parto no Brasil do século XIX
}

Juliana Fonseca da Silva Linhares Bueno

E-mail: linhares.juliana@yahoo.com.br Instituto Federal do Paraná, Paranaguá, Brasi

Cíntia de Souza Batista Tortato E-mail: cintia.tortato@ifpr.edu.br Instituto Federal do Paraná, Paranaguá, Brasil

\section{RESUMO}

O presente artigo objetiva trazer alguns elementos bibliográficos sobre o processo de cientificização das práticas voltadas ao parto no Brasil do século XIX. As parteiras estiveram presentes no Brasil Colônia, desde o século XVI, seu saber tácito era utilizado, tanto para auxiliar as parturientes quanto para cuidar das diversas enfermidades associadas aos órgãos reprodutivos. A vinda da Família Real Portuguesa para o Brasil em 1808 desencadeou; mudanças na colônia. A criação das faculdades de Medina nas cidades de Salvador e Rio de Janeiro foram responsáveis pelo processo de legitimação do saber médico, e a introdução da ginecologia e obstetrícia na região. Busca-se analisar o processo de transição do saber tácito representadas pelas técnicas das parteiras para o saber científico da medicina acadêmica.

PALAVRAS-CHAVE: Parteiras. Medicina moderna. Gênero. CTS 


\section{INTRODUÇÃO}

O corpo feminino sempre esteve relacionado com o ato de gestar e de partejar, funções biológicas da mulher que perpassam a esfera funcional e adentra a esfera simbólica e representativa ao "dar à luz" a um novo ser. Mary Del Priore (apud BARRETTO, 2001, p. 130) salienta que "o momento do parto" até o século XVIII era um ritual exclusivamente feminino, vivenciado pela comunidade "onde o saber era transmitido de mães para filhas, que reunia parturiente, parteira, comadres e vizinhas, numa união calorosa entre o público e o privado". O parto era auxiliado pela parteira que possuía uma técnica artesanal permeada por "valores religiosos, morais, comportamentais" que enchiam de significância cada etapa seguida no ritual, que contava com lubrificantes naturais, cachaça, relíquias religiosas e cordões coloridos eram utilizados para assegurar o parto (DEL PRIORE, 2016, p. 312).

Maria Lúcia Barros Mott (1999, online) complementa Del Priore (2016) ao esclarecer que:

As parteiras acreditavam que sua função era assistir o parto, esperara a natureza se manifestar, e aparar a criança - conseguindo inclusive, através de rezas e rituais, o auxílio benfazejo de santas e santas do panteão católico e das demais forças sobrenaturais.

O ofício das parteiras constituído por um conhecimento tácito tinha como objetivo, ajudar na saúde da mulher gestante ou não gestante. Giselle Barbosa (2014, p. 1) esclarece que "eram mulheres que se dedicavam a ajudar outras mulheres a darem à luz, mas também exerciam outras funções", tais como: auxiliar a gestação, cuidados com o recém-nascido, puerpério e tratar das doenças. Nessa prática do cuidar de toda a esfera feminina, as parteiras eram benquistas pela população. Renilda Barreto (2001, p. 148-150) alega que os "conselhos e cuidados com a parturiente e o recém-nascido" explicam o fato de muitas das parteiras serem chamadas de comadres, pois sua função era honrosa reconhecida e prestigiada nas comunidades onde atuavam.

Presentes no Brasil desde os séculos XVI como uma prática legalizada pela coroa Portuguesa, o prestígio e atuações desse saber milenar perderam seu espaço de atuação no Brasil do século XIX (BARROS MOTT, 1999, on-line). O artigo aqui apresentado, objetiva a partir de um levantamento bibliográfico trazer alguns elementos de discussão sobre o processo de cientificização das práticas voltadas ao parto relacionadas com a saúde da mulher, que buscava construir um mapeamento e racionalização do funcionamento do corpo feminino e sucessivamente a desapropriação do saber empírico das parteiras e a apropriação médico cientifica do mesmo, por meio da Introdução da Obstetrícia e Ginecologia.

Com o advento do movimento feminista e os estudos de gênero se inicia um processo de reflexão e questionamento sobre a ciência androcêntrica até então oficial, propondo um reconhecimento da história, a partir da representação das mulheres que historicamente foram marginalizadas. Por meio dessa perspectiva, procura-se dar voz a mulher, no caso específico deste trabalho, refletir sobre as parteiras enquanto mulheres que possuíam prestígio e representatividade na sociedade brasileira associadas à função exercida, mas que devido a inserção do saber tecnológico e o desenvolvimento da medicina, tiveram sua prática desvalorizada, e consequentemente a privação das mulheres no exercício de seu ofício. Os parâmetros que nortearam o desenvolvimento da Medicina estavam 
baseados na Ciência Moderna, que excluía a mulher do campo científico, "abstraindo, declaradamente, toda possibilidade de considerar as mulheres como sujeitos de conhecimento e do conhecimento" (LETA, 2014, p. 139).

\section{METODOLOGIA}

O trabalho aqui apresentado pretende por meio de uma revisão bibliográfica, problematizar as temáticas já apresentadas, buscando compreender o processo de transição do saber empírico representadas pela técnica da parteira para o saber científico da medicina obstétrica.

O alicerce teórico que sustenta esse artigo consiste nos estudos de Ciência, Tecnologia e Sociedade (CTS), campo interdisciplinar que de acordo com Renato Dagnino (2014, p. 56), objetiva entender os fenômenos "científico-tecnológico no contexto social, tanto em relação com os seus condicionantes sociais quanto ao que se refere às suas consequências sociais". Para Vieira Pinto (2011) a técnica é coetânea ao homem, acumulativa e transmitida culturalmente. Sendo assim, está presente em toda a história da humanidade. Já a tecnologia, de acordo com Rui Gama (1985), é a aplicação metodológica do conhecimento científico.

\section{DAS PARTEIRAS À MEDICINA DA MULHER: Uma breve reflexão}

As parteiras estão presentes na história do Brasil desde as primeiras décadas da colonização. Em Portugal o exercício do ofício era reconhecido, entretanto, era necessário obter uma licença especial para praticá-la, tanto na Metrópole quanto na Colônia. No Brasil, não existia um órgão específico para fiscalizar os ofícios de cura, sendo assim, a responsabilidade foi incumbida as Câmaras Municipais (BARROS MOTT, 1999, on-line).

Presentes em todo o território brasileiro eram denominadas por diferentes terminologias, tais como: Parteiras, comadres, aparadeiras, assistentes etc., entretanto a função exercida era a mesma. $\mathrm{O}$ atendimento poderia ocorrer na casa da paciente ou na casa da parteira. Luiz Felipe Alencastro (1997, p. 72-73) esclarece que a casas das parteiras eram marcadas com um "sinal lúgubre" de "uma cruz preta, indicando à profissão". A simbologia representava a dualidade da profissão, pois o "ofício tratava tanto da vida como da morte" e quando uma parteira "saía para trabalhar quase sempre havia um luto: ou morria a mãe ou morria o bebê".

Beatriz Weber (1999) esclarece que, a função exercida pelas parteiras ultrapassava o cuidado e adentrava a esfera particular das pacientes:

As parteiras compartilhavam das vidas das mulheres que tratavam, resolvendo seus 'incômodos', guardando seus segredos e mantendo suas amizades. Eram mulheres que exerciam os mesmos papéis cotidianos que as demais, mas também podiam dar o socorro no caso de alguma doença e, principalmente, ajudavam mulheres a 'dar à luz'. Tinham uma profunda inserção no quotidiano do espaço doméstico, incluindo as crianças, os vizinhos, os parentes, num universo governado pelos valores femininos (WEBER, 1999, p. 178).

As Parteiras possuíam um conhecimento vasto sobre o corpo e saúde da mulher, Londa Schiebinger (2001, p. 209) salienta que elas eram especialistas em saúde da mulher, seu conhecimento tradicional era transmitido "através da rede 
de relações entre as mulheres, de mãe para filha e de parteira para vizinha". Beatriz Weber (1999, p. 178) complementa Londa Schiebinger (2001) ao destacar que o conhecimento prático ocorria "provavelmente no contato com outras parteiras mais velhas, que guardavam conhecimentos do funcionamento do corpo feminino que não eram comuns".

Miguel Angel Quintanilla (2016, p. 87) ao refletir sobre a técnica argumenta que a mesma consiste em "um conjunto de conhecimentos que servem para resolver problemas práticos" e "são entidades culturais ou formas de conhecimento: algo que se pode apreender e transmitir através de diferentes processos de aprendizagem". Segundo Viera Pinto (2001, p.136-137) a técnica é "uma propriedade inerente à ação humana sobre o mundo e exprime por essência a qualidade do homem, como ser vivo" ela não se dicotomiza da cultura, pois ambas estão ligadas ao homem desde sua forma embrionária. A partir desta reflexão, podemos perceber o conhecimento empírico das parteiras como um conhecimento técnico.

A função da parteira perpassava o auxílio à parturiente, cuidavam de diversos "incômodos do útero", ou seja, "diversas doenças venéreas, inflamações" que eram tratadas com "lavagens de água fervida e líquidos 'perfumosos', tampões de tecido introduzidos no útero (curativos), 'sublimados corrosivos" (WEBER, 1991, p. 178), tinham um "grande conhecimento sobre uso de plantas e ervas medicinais" para tratamento de doentes (AQUINO, 2006, p. 12) e possuíam um vasto repertório de métodos contraceptivos e abortivos. Londa Schiebinger (2001, p. 210) destaca que elas "tinham acesso a mais de 200 contraceptivos e abortivos" que foram apagados com o estabelecimento da medicina moderna.

Barreto (2001, p. 146) observa que os "procedimentos técnicos desenvolvidos" pelas parteiras estavam repletos de "valores religiosos, morais, comportamentais" que "representa uma nuance da multifacetada forma de apropriação da cultura do corpo na sociedade" brasileira. A busca de proteção durante o parto no culto realizado para as santas "Nossa Senhora do Amparo, Nossa Senhora da Luz, Nossa Senhora da Glória", ressalta o apelo religioso relacionado ao "temor e risco de morrer no memento do nascimento" (ALENCASTRO, 1997, p. 71).

Mott (1999, on-line) enfatiza que as parteiras possuíram um "saber elaborado a partir das crenças religiosas" e "práticas populares", acreditavam que "através de rezas e rituais" e apelo os santos católicos e outras "forças sobrenaturais" elas poderiam conduzir a chegada da criança. Del Priori (2016, p. 312) esclarece que as funções "mágico-religiosas" desempenhadas durante o parto objetivavam "atrair a criança para fora da barriga da mãe", as mesmas vinham "ao mundo entre preces, gritos de dor e júbilo".

Sobre a esfera feminina as parteiras eram a "maior autoridade, devido" a magnitude de seu saber (WEBER, 1999, p.178). Prestigiadas e reconhecidas nas "comunidades onde atuavam", tratadas com respeito, pois "eram responsáveis por acompanhar o nascimento e ajudar a parturiente em momentos de grande dor e aflição", além de auxiliar a mulher em diferentes problemas de natureza feminina, ademais, ofereciam alívio e conforto psicológico e espiritual. Obstante, essa esfera harmoniosa não se manteve no século XIX.

Com a transferência da Família Real para o Brasil em 1808, aconteceram na Colônia transformações até então não ocorridas. As medidas adotadas buscavam 
estabelecer instituições locais para atender as demandas da aristocracia portuguesa estabelecida no país. A criação das Escolas de Cirurgia nas cidades do Rio de Janeiro e Bahia foi um "item fundamental" para a "modernização do território brasileiro e também de produção de uma cultura científica" sendo que "anteriormente não havia sido permitida a criação de instituições superiores". Outro fator que contribuiu para a abertura das mesmas foi à tentativa de aumentar o "número de médicos" que era insuficiente no território brasileiro (OLIVEIRA, 2016, p. 27-29).

O processo de cientificização das práticas de cura no Brasil acarretou ao aperfeiçoamento da Fisicatura-Mor, órgão "responsável pela fiscalização referente à higiene pública, exercício da medicina, cirurgia e parteiras" (BARROS MOTT, 1999, on-line). A Fisicatura - Mor consistia em um juizado privativo que era dividido entre as funções: físico-mor e cirurgião-mor, responsáveis por verificar se as "questões relacionadas à medicina, boticários, venda de drogas medicinais, bebidas e curandeiros" (dentistas, cirurgiões, sangradores e parteiras) ocorriam de acordo com as normativas da Coroa/Império (PIMENTA, 1997, p.12).

As parteiras precisavam de uma licença para exercer o seu ofício, o procedimento de licenciamento era composto por duas etapas, sendo a primeira a apresentação de uma carta "comprovando a experiência que deveria ser apresentada ao representante do físico mor da região em que vivia" e a segunda consistia em um exame onde a parteira era "avaliada por dois cirurgiões e uma parteira aprovada", durante o exame eram feitas "perguntas sobre a teoria e prática do oficio, se aprovada recebia" a licença (BARROS MOTT, 1999, on-line).

Fabíola Rohden (2006, p. 214-215) esclarece que, de uma forma geral, a medicina não se interessava pelas "enfermidades femininas" e a "marginalidade do corpo feminino, teria a ver com o desprezo mais geral sobre a manifestação do corpo" da mulher. $\mathrm{O}$ atendimento médico, em um primeiro momento no Brasil se restringia aos casos graves, "de complicação de parto que colocassem em rico as mulheres e crianças", sendo assim, as outras funções foram delegadas as parteiras que passaram a ter o seu ofício controlado pelos médicos.

O discurso médico higienista atribuía à mulher um "pressuposto de inferioridade", representada por estereótipos negativos e "associada à sua inferioridade intelectual, à sua delicadeza física e ao instinto materno". Com atuação social restrita eram irrelevantes para as instituições como Estado e Igreja (SANTOS; SALLES, 2015, p. 121-122).

Tânia Pimenta (1997, p. 4) observa que desde a "vinda da Corte" para o Brasil, o número de "médicos e cirurgiões" aumentou significativamente ademais, a criação das Escolas de Cirurgia em 1808 e posteriormente a transformação das mesmas em Faculdades de Medicina em 1832, institucionalizou o ensino no país, e criou uma elite médica local que objetivava o "monopólio legal do exercício da arte de curar" e a "medicalização da sociedade". Barreto (2001, p. 133) enfatiza que a partir da criação das escolas de medicina, "caberá aos médicos a missão civilizadora (...) extirpando todo e qualquer elemento que pudesse caracterizar o Brasil como nação atrasada".

De acordo com a concepção positivista a ciência era a fonte da verdade absoluta e mecanismo responsável pelo progresso social. Isto posto, a missão civilizadora no Brasil oitocentista era baseada nos ideais positivistas que objetivava o desenvolvimento da ciência e sucessivamente a extinção das práticas tradicionais 
de cura. Outrossim, os discursos científicos do século XIX foram influenciados pela concepção racista e eugenista do darwinismo social que pregava a superioridade física e intelectual das raças, sendo o europeu branco o ápice evolutivo a "seleção natural era a força motriz para a transformação da sociedade" a partir dessa concepção o Brasil era tido como uma nação atrasada, pois sua população miscigenada era considerada uma raça inferior (SANTOS; SALLES, 2015, p. 121127).

A extinção da Fisicatura-Mor em 1828 dificultou a "atuação das terapias populares" e direcionou para as Faculdades de Medicina, o papel de "fornecer titulação e permissão para as parteiras" (BARBOSA, 2014, p. 2). Mott (1999, online) adverte que após a abertura das faculdades de medicina, as mulheres que gostariam de exercer a "profissão de parteiras deveriam, a partir de então, fazer (...) o curso de partos", que buscava ensinar "de acordo com o preceito da ciência correta à maneira de atender a mulher e os primeiros cuidados com a criança" (ROHDEN, 2006, p.214).

As parteiras aprovadas nos "exames admissionais deveriam fazer juramento" no final do curso e se "comprometer a cumprir a cláusula que limitava a sua atuação", sendo assim, em caso de partos difíceis que durasse mais de vinte e quatro horas, o médico deveria ser chamado, a parteira não podia administrar nenhum tipo de "medicamento ou acessórios no ato de partejar" (BARBOSA, 2014, p. 3-5). Ademais, se pode perceber que a partir do mecanismo de controle, apoiado pelo Estado, ocorreu à submissão do saber tácito feminino pelo saber científico, racionalizado e elitizado masculino, tal procedimento foi utilizado para reintegrar a mulher seu papel de submissão socialmente atribuído.

A extinção da Fisicatura-Mor pode ser percebida como uma tentativa de extinguir as terapias populares e consolidar medicina acadêmica no país. Essa tendência não se limitou a medidas direcionadas como dificultar o exercício do ofício, mas também se inseriu no âmbito simbólico, com "campanhas de difamação" e "ridicularizarão" das práticas tradicionais, "mesmo sendo o seu saber tributário na medicina clássica, transferido por incontáveis gerações" (BARROS MOTT, 1999, on-line). Sônia Maria Magalhães (2011) esclarece que a "consolidação da medicina científica perante a sociedade constitui um processo conflituoso e lento", pois a institucionalização, objetivo da elite médica brasileira "significou a ruptura" com práticas seculares (MAGALHÃES, 2011, p. 1098).

O estabelecimento da Medicina Moderna no país contribuiu para o surgimento da medicina da mulher e isso ocorreu devido ao desenvolvimento de técnicas básicas, tais como toque, auscultação fetal, pelvimetria, controle das infecções puerperais, parto provocado, e anestesia para aliviar a dor. O início do século XIX, o "estudo e tratamento do aparelho reprodutivo e das doenças femininas, confundiam-se com a obstetrícia", posteriormente ocorreu uma separação para "dois ramos" distintos da medicina, sendo: 10 Obstetrícia - campo destinado para a "gravidez, parto e puerpério", sua prática estava relacionada com a experiência clínica. 2 ㅇ Ginecologia - "que se dedicava ao estudo morfológico, fisiológico e patológico do organismo feminino e aparelho genital", surge como uma "especificidade clínica (ROHDEN, 2002, p. 105-108).

Para Mott (1999, on-line) o ensino da Medicina da mulher no Brasil do século XIX era irrisório, as faculdades, "não preparavam os profissionais para fazer partos", as aulas eram orais, "onde repetiam exatamente o que estava escrito nos 
manuais. Não havia aula prática, já que não havia uma clínica de partos". Na obra a autora traz um relato do médico "Anselmo da Fonseca" que relembra:

A monotonia daquele curso fastidioso só era quebrada pelos manejos realizados sobre um manequim, que, com alguns esqueletos de bacia, úteros e fetos artificiais e diversos instrumentos, constituíam os únicos elementos com que se deveriam habilitar e formar os futuros parteiros. No fim do ano os estudantes eram aprovados sem terem jamais assistido a um parto, nem uma vez sequer praticado o simples toquei (FONSECA apud BARROS MOTT, 1999, on-line).

Essa precarização do ensino médico não foi restrita ao campo da medicina da mulher, o mesmo estava relacionado ao processo de cientificização da prática no Brasil. Gabriela Sampaio (2005) chama a atenção para o fato de que, o processo de consolidação enfrentou diversos problemas: desde a falta professores e estrutura física até de falta de consenso nos procedimentos adotados. A "medicina oferecia tratamentos agressivos e dolorosos" e a introdução de técnicas polêmicas como: fórceps, cesariana e manobra de Mauriceau, contribuíram para a dificuldade de "aceitação da participação do médico na obstetrícia" (ROHDEN, 2006, p. 213). Beatriz Weber (2004) cita em sua obra, uma notícia de jornal que denunciava uma cesariana malsucedida:

Haverá operação mais cruel? Quantas dores sofreu a pobre parturiente, aguentando tamanha barbaridade e tanta desumanidade do parto de seus algozes? Depois de serrarem o osso da bacia, abriram à força para dar passagem livre ao feto que nasceu com vida; porém a infeliz senhora, 24 horas após a bárbara operação, exalava seu último alento, no meio das mais cruciantes dores e hemorragias, que eles não conseguiram aplacar quanto mais estancar. Foi nessas condições que morreu uma distinta senhora na flor da idade, acabando seus dias nas mãos de homens que não eram ignorantes, nem precisaram se acobertar com alei da liberdade profissional. (O Exemplo, 10 abr. 1910:1 apud WEBER, 2004, p. 159)

Rohden (2002, p. 112) esclarece sobre as "dificuldades morais" em aceitar a participação de "um homem estranho, mesmo coberto pelos propósitos da medicina, na intimidade de uma mulher era um dos temas de debate" da época. Ana Paula Martins (2005, p. 656) "comenta que a vergonha feminina em mostrar o corpo para o médico era" recorrente no século XIX. Outro fator que contribuía para o estranhamento estava relacionado com o sentimento de posse exercido pelo marido sobre o corpo feminino, o que trouxe grandes polêmicas para o exercício da medicina da mulher.

Barreto (2001, p. 141) observa que as mulheres preferiam ser auxiliadas em período de enfermidade, "por outras mulheres, principalmente ao que diz respeito às doenças exclusivamente femininas". A parteira Romana de Oliveira ao falar sobre sua função informa que é um ato de natureza feminina, que requer "assistência de mulher e não de homem" (MOTT, 1999).

O reconhecimento profissional das parteiras se manteve, mesmo após a institucionalização da medicina no Brasil. Cabe esclarecer que nem todas as parteiras possuíam licença para exercer o ofício, mas isso não as limitava no 
emprego de suas funções. Barbosa (2014) observa que as licenças eram caras e que as parteiras só buscavam a regulamentação do ofício após serem denunciadas.

Entretanto, seu repertório técnico sobre a saúde da mulher, por um período, foi mais significativo que o dos próprios médicos oitocentistas, sendo que muitos se apropriaram dessas técnicas ao decorrer dos anos. Um fato que corrobora para esse perfil foi à falta de interesse da classe médica de desempenhar essa função. A obstetrícia, não era um campo de prestígio, por isso, foram atribuídas às parteiras (ROHDEN, 2006). Mott (1999, on-line) enfatiza que até mesmo o atendimento das esposas dos médicos era realizado pelas parteiras, em outras esferas familiares, elas continuavam a auxiliar todos os membros da família em períodos de doença, pois pertenciam ao círculo de confiança.

Sampaio (2005) esclarece que a popularização da medicina no Brasil, desencadeou a rivalidade profissional entre os médicos locais "a falta de consenso sobre os procedimentos", "questões de honorários [ e ] médicos que acusaram outros médicos de matar seus pacientes" caracterizam um período de transformação da "medicina científica, que vinha adquirindo muita influência (...) na sociedade brasileira". Entretanto a luta pela legitimação da classe, em "diversos setores sociais" se contrapunha ao medo generalizado da população pela medicina acadêmica.

A cirurgia era uma das categorias médicas que mais despertavam o medo da população. "Por isso, os cirurgiões buscaram um "mercado que pusessem atuar sem competir com" outras categorias e "optaram pela parturição" (BARBOSA, 2014 , p. 5). A profissionalização abriu espaço para a formação de uma profissão e ocupação de um nicho de mercado. Os saberes já não eram adquiridos na prática, de mães ou avós para filhas, de mulheres para mulheres, mas por instituições desconectadas das questões que transcendiam a fisiologia dos corpos.

O campo da Obstetrícia tornou-se atraente, "sobretudo o atendimento normal - sucesso garantido para o profissional, um parto bem-sucedido poderia significar tornar-se médico da família", assim "sendo requisitado (...) para cuidar de diferentes doenças" que assolassem os "membros da família". (MOTT, 1999, on-line). Para conseguir o prestígio popular, os médicos obstetras passaram a realizar atendimento gratuito para a população carente, mecanismo "para ganhar a confiança das camadas populares, aqueles que tradicionalmente recorreriam ao auxílio das parteiras" (BARRETO, 2001, p. 142).

Sendo assim, as parteiras tiveram o seu "espaço de atuação reduzido" e as "mulheres que viviam dessa prática" passaram a ser "socialmente criminalizadas". Esse processo de descriminalização foi fruto de diversos mecanismos utilizados para legitimar a medicina acadêmica Brasil, entre eles, pode-se destacar a "campanha difamatória" que buscava associar "a imagem da parteira como mulher ignorante, analfabeta, sem moral, responsável pela morte de mães e recémnascidos", sem "qualificação profissional", caracterizado assim, uma luta simbólica entre a "ciência e não ciência, racionalidade e superstição" (MOTT, 1999).

Ademais, Rohden (2002) esclarece que no século XIX, a representação social da mulher era de submissão e esfera particular, ou seja, cabia à mulher as funções relacionadas ao cuidado da família e a maternidade, e qualquer alteração na esfera desestabilizariam a "ordem patriarcal" (ROHDEN, 2002 p. 115-156). As parteiras ao desempenharem seu ofício, mexiam com a estrutura social estabelecida, pois desempenhavam uma função de prestígio na sociedade, mesmo sendo a maioria 
analfabeta e competiam diretamente com a classe médica, que se anunciava a detentora do saber legitimo da arte de curar. Barros Mott (1999, on-line) salienta que o preconceito contra as parteiras, também estava relacionado à "origem étnico-racial" (BARROS MOTT, 1999).

Com o processo de cientificização, ocorrido em meados do século XIX, iniciouse uma campanha de "transformação do parto num evento controlado" pela medicina e "exclusivo do ambiente hospitalar" (BARBOSA, 2014, p. 6). A medicina passa a desempenhar um papel de controle sobre o corpo feminino, pois:

O conhecimento do mecanismo do parto teve grande impacto na extensão do controle médico sobre o corpo feminino. A obstetrícia tornara-se um estudo preciso, quase matemático, ao transformar o corpo materno num espaço analisável, mensurável e passível de intervenção (MARTINS, 2005, p. 662)

Ademais, tornou-se responsável pela patologização do parto e seu deslocamento da esfera particular para a esfera pública. A patologização transformou o parto em um procedimento clínico e:

\begin{abstract}
Manipulado pelas mãos do médico, (...) que exigia da mulher adotar certas posições e permanecer imóvel, o que nem sempre ocorria, pois, muitas mulheres não aceitavam o toque vaginal e preferiam movimentar-se quando sentiam as contrações. Alguns médicos aceitavam esses comportamentos, mas a tendência foi convencer a parturiente de que quanto mais ela colaborasse com o médico, deixando-se examinar, melhor seria o atendimento e mais seguros os resultados (MARTINS, 2005, p. 662).
\end{abstract}

Esse procedimento dificultou a participação das parteiras no exercício de seu ofício. $O$ trabalho das parteiras tornou-se limitado ao ato de cuidar, o que era ainda visto como capacidade inerente a natureza feminina. Barreto (2001) observa que a "racionalidade científica oitocentista (...) passa a formar um modelo específico para a vida e a morte do corpo" criando "uma nova ordem das representações", e o "conhecimento do corpo mulher", foi utilizado como instrumento de controle, "condenando todo e qualquer hábito (...) que impossibilitasse" o não cumprimento do papel social estabelecido (BARRETO, 2001, p. 132- 143). Esse papel de normatização do corpo feminino foi atribuído a ginecologia que "definiu-se enquanto a especialidade guardiã da honra feminina e da regulamentação das manifestações corporais da mulher" (ROHDEN, 2002. 113).

Quintanilla (2016, p. 87) ao discorrer sobre as características da tecnologia salienta que a mesma consiste em um "conjunto de conhecimentos de base científica que permite descrever, explicar e aplicar soluções técnicas (...) de formas sistêmicas e racionais". Bazzo (2003, p. 44) chama a atenção ao fato de que nem toda a tecnologia é composta por um artefato, a mesma pode ser um sistema fundado no conhecimento científico, ou seja, uma "tecnologia de caráter organizativo".

Desta forma, se pode compreender a medicina como uma tecnologia de caráter organizativo, que no processo de cientificização iniciado no século XIX no Brasil, utilizou-se de diferentes mecanismos para se afirmar como a única detentora legitimada e autorizada para intervir no corpo humano (MOTT, 1999). 


\section{CONSIDERAÇÕES FINAIS}

A partir das discussões acima desenvolvidas, pode-se compreender o processo de cientificização do parto, ocorridos ao decorrer do século XIX. O ofício das parteiras, técnica milenar, embasada em um conhecimento tácito, transmitido por meio de uma rede de relações socioculturais femininas perdeu seu espaço após o processo de institucionalização da Medicina no Brasil que, por sua vez, surge como um conhecimento embrionário destituído de metodologias e consenso em relação os procedimentos adotados e, mesmo assim conseguiu se estabelecer como a única, detentora legitima da arte de curar, baseando-se no argumento da racionalização científica. O processo de institucionalização da medicina, não ocorreu de forma unânime, e utilizou-se de diferentes estratégias para conseguir aceitação social.

A Medicina da Mulher, uma especificidade da Medicina Moderna surge, graças ao desenvolvimento tecnológico até então não ocorridos ou não reconhecidos, nos quais podemos citar: Anestesia, assepsia, antissepsia etc. A mesma foi utilizada como um mecanismo de dominação social que objetiva legitimar a ordem patriarcal socialmente estabelecida, e assegurar a limitação da mulher na participação da esfera particular da sociedade.

Partejar, arte milenar de auxiliar a mulher durante o parto consistia em um ato exclusivamente feminino, que permeava diferentes esferas sociais, culturais, religiosa, mística etc. A parteira, mulher que desenvolvia uma função pública, prestigiada pela a sociedade e associada ao conhecimento, passou a ser perseguida e difamada com o surgimento da Medicina da Mulher, em princípio, tendo sua função controlada pelo médico e posteriormente limitada ao papel do cuidar, ou seja, sem nenhuma autonomia para exercer seu ofício. 


\title{
From midwives to obstetric medicine: a brief reflection on the scientific process of childbirth in nineteenth century Brazil
}

\begin{abstract}
This article aims to bring some bibliographical elements about the scientific process of labor practices in Brazil in the 19th century. The midwives were present in Brazil Colony, since the sixteenth century, their tacit knowledge was used, both to assist the parturients and to take care of the various diseases associated with the reproductive organs. The coming of the Portuguese Royal Family to Brazil in 1808 triggered, changes in the colony. The creation of the faculties of Medina in the cities of Salvador and Rio de Janeiro were responsible for the legitimation of medical knowledge and the introduction of gynecology and obstetrics in the region. The aim is to analyze the transition process of tacit knowledge represented by the midwifery technique to the scientific knowledge of academic medicine.
\end{abstract}

KEYWORDS: Midwives. Modern medicine. Gendre. CTS.

\section{De las parteras a la medicina obstétrica: Una breve reflexión sobre el proceso de cientificiación del parto en el Brasil del siglo XIX}

\begin{abstract}
RESUMEN
El presente artículo tiene por objeto traer algunos elementos bibliográficos sobre el proceso de cientificiación de las prácticas orientadas al parto en el Brasil del siglo XIX. Las parteras estuvieron presentes en Brasil Colonia, desde el siglo XVI, su saber tácito era utilizado, tanto para auxiliar a las parturientas y para cuidar de las diversas enfermedades asociadas a los órganos reproductivos. La llegada de la familia real portuguesa a Brasil en 1808 desencadenó; cambios en la colonia. La creación de las facultades de Medina en las ciudades de Salvador y Río de Janeiro fueron responsables del proceso de legitimación del saber médico, y la introducción de la ginecología y obstetricia en la región. Se busca analizar el proceso de transición del saber tácito representadas por las técnicas de las parteras para el saber científico de la medicina académica.
\end{abstract}

PALABRAS CLAVE: Parteras. Medicina moderna. Género. CTS. 


\section{REFERÊNCIAS}

ALENCASTRO, Luiz Felipe (org.) História da Vida Privada no Brasil. São Paulo: Cia. das Letras, 1997.

AQUINO, Estela. M. L. Gênero e ciência no Brasil: contribuições para pensar a ação política na busca da equidade. In: BRASIL. Secretaria Especial de Políticas para as Mulheres. Encontro nacional pensando gênero e ciência: núcleos e grupos de pesquisas. Brasília, p. 11-18, 2006.

BARBOSA, Giselle Machado. Condições preliminares sobre as parteiras legalizadas pela Fisicatura-Mor a partir dos registros de confirmação de licença (1808-1828). In: XVI encontro Regional de História da Anpuh-Rio: Saberes e práticas científicas. Anais..., 2014.

BARRETO, Renilda. Corpo da mulher: a trajetória do desconhecido na Bahia do século XIX. História: Questões e debates, 34, p. 127-156, 2001.

BARROS MOTT, Maria Lúcia. A parteira ignorante: um erro de diagnóstico médico? Estudos Feministas; Florianópolis v. 7, n. 1 e 2, 1999.

BAZZO, Walter Antonio et al. Introdução aos estudos CTS: O que é Ciência, Tecnologia e Sociedade? Cadernos de Ibero-América, Editora OEI, 2003.

DAGNINO, R. BRANDÃO, F.C; NOVAES, H. T. Sobre o marco analíticoconceitual da Tecnologia Social. In: Antonio de Paulo et al.. (Org.) Tecnologia Social: uma estratégia para o desenvolvimento. Rio de Janeiro: Fundação Banco do Brasil, 2004, p. 15-64.

DEL PRIORI, Mary. Histórias da gente brasileira. V.1: Colônia. São Paulo: LeYa, 2016.

GAMA, Rui. História da técnica e da tecnologia. São Paulo: Edusp, 1985.

LETA, Jacqueline. Mulheres na Ciência Brasileira: desempenho inferior?. Revista feminismos, v. 2, n. 3, p. 139-152, set./dez., 2014.

MAGALHÃES, Sonia Maria de. Batalha contra o charlatanismo: Institucionalização da medicina científica na província de Goiás. História, Ciências, SaúdeManguinhos, Rio de Janeiro, v. 18, n.4, p. 1095-1109 out.-dez. 2011.

MARTINS, Ana Paula Vosne. A ciência dos partos: visões do corpo feminino na constituição da obstetrícia científica no século XIX. Estudos Feministas, Florianópolis, 13(3), p. 645-665, set./-dez.,2005.

OLIVEIRA, Pedro Henrique Ferreira Danese. Institucionalização do alienismo nos períodos médicos ( Rio de Janeiro, 1832-1852). 182 f. Dissertação (Mestrado), Pós-Graduação em História das Ciências e da Saúde, Fundação Oscaldo Cruz, Casa de Oswaldo Cruz, Rio de Janeiro, 2016. 
Universidade Estadual de Campinas, Instituto de Filosofia e Ciencias Humanas, Campinas, SP, 1997.

PINTO, Álvaro Vieira. O conceito de tecnologia. V. I. Rio de Janeiro: Contraponto, 2005.

QUINTANILLA, Miguel Angel. Técnica e Cultura. Revista Guairacá de filosofia, Guarapuava-Pr, v. 32, n. 2, p. 85-105, 2016.

ROHDEN, Fabíola. Ginecologia, gênero e sexualidade na ciência do século XIX. Horiz. antropol.Porto Alegre, v. 8, n. 17, p. 101-125,jun., 2002.

ROHDEN, Fabíola. Histórias e tensões em torno da medicalização da reprodução. Gênero, Niterói, v. 6, n.1, p213-224, 2006.

SAMPAIO, Gabriela dos Reis. Nas Trincheiras da Cura. As diferentes medicinas no Rio de Janeiro Imperial. Campinas: Editora da UNICAMP, 2005.

SANTOS, Maria Ap. Conceição Mendonça; SALLES, Vera Lúcia Rolim. O corpo em transe: A moral sexual sobre o corpo feminino no Brasil no final do século XIX e início do XX. Revista Estação Literária, Londrina, v. 13, p. 120-132, jan., 2015.

\section{SCHIEBINGER, Londa. O feminismo mudou a ciência? Bauru-SP, EDUSC, 2001}

WEBER, Beatriz Teixeira. Fragmentos de um mundo oculto: práticas de cura no sul do Brasil. In: Hochman Gilberto, organizador. Cuidar, controlar e curar: ensaios históricos sobre saúde e doença na América Latina. Rio de Janeiro: Fiocruz; 2004. p. 157-216.

Recebido: 25/09/2018

Aprovado: 20/06/2019.

DOI: $10.3895 /$ cgt.v12n40.8866

Como citar: BUENO, Juliana Fonseca da Silva Linhares; TORTATO, Cíntia de Souza Batista. Das parteiras

à medicina obstétrica: Uma breve reflexão sobre o processo de cientifização do parto no Brasil do século

XIX. Cad. Gên. Tecnol., Curitiba, v. 12 n. 40, p. 265-277, jul./dez. 2018. Disponível em:

https://periodicos.utfpr.edu.br/cgt. Acesso em: XXX

Correspondência:

Juliana Fonseca da Silva Linhares Bueno

Rua: Adir Pedroso 570, bl 07, ap 407 - São José dos Pinhais, Paraná, Brasil

Direito autoral: Este artigo está licenciado sob os termos da Licença Creative Commons-Atribuição 4.0

Internacional.

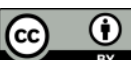

